\title{
CONF-950905--13
}

UCRL-JC-121152

PREPRINT

\section{TPX Superconducting Tokamak Magnet System 1995 Design and Status Overview}
G. Deis
R. Hale
H. Bell
P. Rackov
W. Bensiek
C. Rey
R. Carpenter
S. Jeong
T. Brandesberg
R. Ryan
A. Corpuz
G. Swartzback
E. Cassidy
P. Michael
R. Smith
M. LaJeunesse
W. Urban
R. Pillsbury Jr.
P. Conde
P. McAuliffe
A. Burger
M. Chaplin
S. Purrahimi
R. DeKoven
D. Stutski
C. Molteni
I. Clarkson
A. Radovinsky K. Grut
W. Tong
R. Parman
J. Schulteiss
S. Hibbs
J. Schultz
D. Johanson
D. Potter
P. Walstrom
M. Jackson
A. Shajii
D. Hoffman
J. VandeBogart
O. Christianson
C. Weber
W. Hannan
D. Hartman
G. Korbel
S. Smith
B. Holt
M. Takayasu
R. Whitfield
R. Hillenbrand
G. Naumovich
D. Lang
E. Hook
N. Martovetsky
P. Wang
$X$. Huang
B. Wilmer
J. Hordabay
J. Parker
J. Citrolo
R. Kunz
M. Xu
D. Johnson
L. Pedrotti
R. L. Myatt
G. Lehman
W. Young
M. Krefta
S. Shen
N. Albritton
C. Gibson
T. Kupisewski
E. Southwick
Y. Lvovsky
D. Alger
J. Maloney
J. Leuer
J. Lowry
C. Wendland
T. Antaya
G. Markham
J. Luxom
J. Roach
J. Zbasnik
R. Batchelder
J. Meissner
H. Calvin
C. Cesar
P. Sanger
S. Singh

This paper was prepared for submittal to 16th IEEE/NPSS Symposium on Fusion Engineering Champaign, Illinois

September 30 to October 5, 1995

September 29, 1995

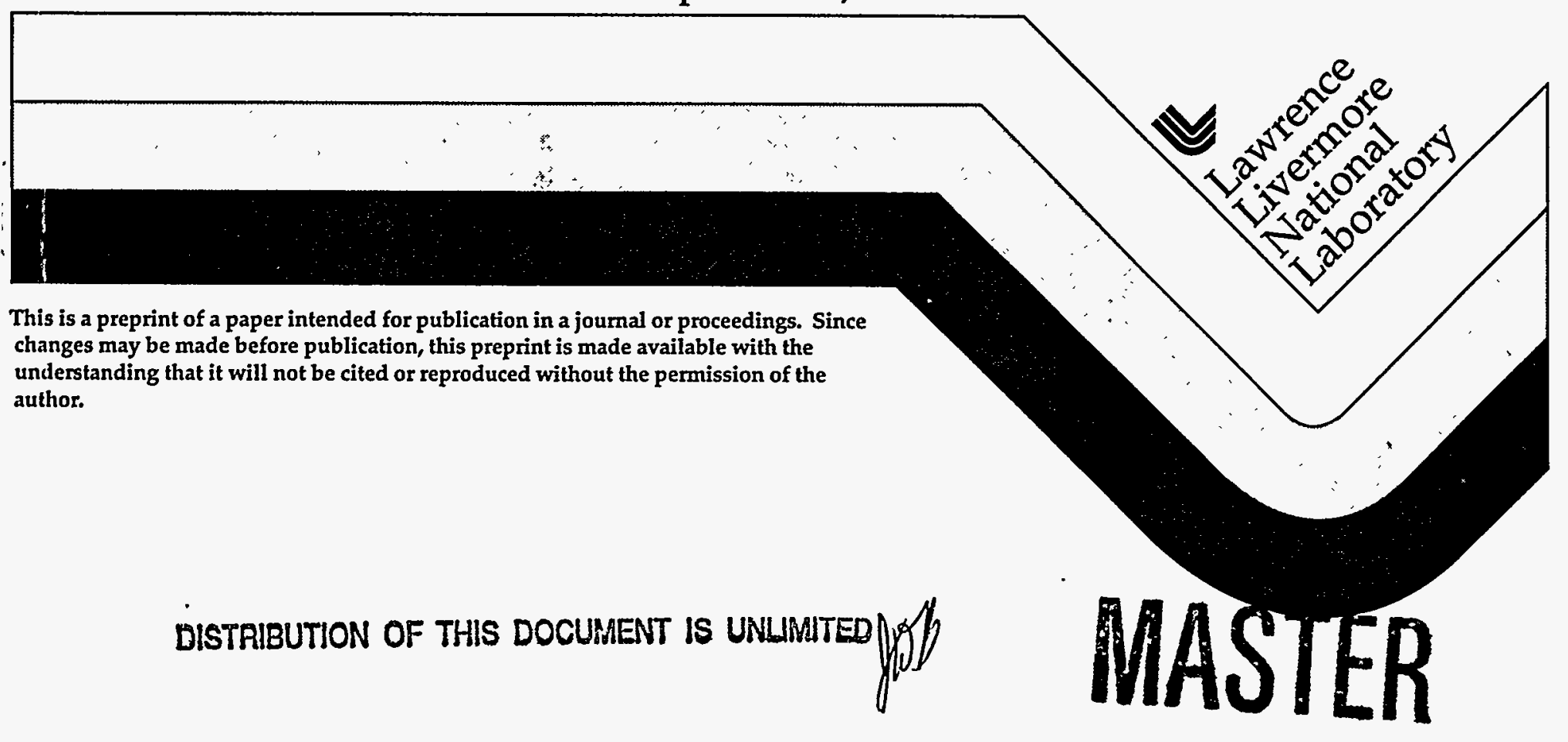




\section{DISCLAIMER}

This document was prepared as an account of work sponsored by an agency of the United States Government. Neither the United States Government nor the University of California nor any of their employees, makes any warranty, express or implied, or assumes any legal liability or responsibility for the accuracy, completeness, or usefulness of any information, apparatus, product, or process disclosed, or represents that its use would not infringe privately owned rights. Reference herein to any specific commercial product, process, or service by trade name, trademark, manufacturer, or otherwise, does not necessarily constitute or imply its endorsement, recommendation, or favoring by the United States Government or the University of California. The views and opinions of authors expressed herein do not necessarily state or reflect those of the United States Government or the University of California, and shall not be used for advertising or product endorsement purposes. 


\section{DISCLAIMER}

Portions of this document may be illegible in electronic image products. Images are produced from the best available original document. 


\section{TPX Superconducting Tokamak Magnet System 1995 Design and Status Overview}

G. Deis, R. Bulmer, R. Carpenter, E. Cassidy, M. Chaplin, B. Felker, S. Hibbs, M. Jackson, G. Korbel, D. Lang, N. Martovetsky, J. Parker, L. Pedrotti, S. Shen, E. Southwick, C. Wendland, J. Zbasnik Lawrence Livermore National Laboratory (LLNL), 7000 East Avenue, PO Box 808, L-643, Livermore CA 94550

R. Hale, S. Jeong, P. Michael, R. Pillsbury Jr., S. Pourrahimi, A. Radovinsky, J. Schultz, A. Shajii, S. Smith, M. Takayasu, P. Wang

Massachusetts Institute of Technology Plasma Fusion Center (MITPFC), 175 Albany Street, Cambridge, MA 02139

$$
\text { J. Citrolo }
$$

Princeton Plasma Physics Laboratory (PPPL), P.O. Box 451, Princeton, NJ 08543

R. Leonard Myatt

Stone and Webster Engineering Corporation, Boston, MA, working for MIT Plasma Fusion Center

N. Albritton, D. Alger, T. Antaya, R. Batchelder, H. Bell, W. Bensiek, T. Brandesberg, P. Conde, R. deKoven, K. Grut, D. Johanson, D. Hoffman, B. Holt, E. Hook, X. Huang, R. Kunz, G. Lehman, Y. Lvovsky, J. Maloney, G. Markham, J. Meissner, P. Rackov, C. Rey, R. Ryan, R. Smith, D. Stutski,

W. Tong, J. VandeBogart, C. Weber, R. Whitfield, B. Wilmer, M. Xu, W. Young

Babcock and Wilcox Corporation (B\&W), P.O. Box 785, Mt. Athos Road, Lynchburg, VA 24504-0785

$$
\begin{aligned}
& \text { C. Gibson, J. Leuer, J. Luxom } \\
& \text { General Atomics, } 3483 \text { Dunhill St., San Diego, CA 92121-1194 }
\end{aligned}
$$

H. Calvin, C. Cesar, A. Corpuz, M. LaJeunesse, P. McAuliffe, C. Molteni,R. Parman, D. Potter

Westinghouse Electric Corporation (WEC), 401 East Hendy Avenue, Sunnyvale, CA 94088-3499

O. Christianson, W. Hannan, R. Hillenbrand, J. Hordabay, D. Johnson, M. Krefta, T. Kupisewski, J. Lowry, J. Roach, P. Sanger, S. Singh, G. Swartzback, W. Urban

Westinghouse Electric Corporation Science and Technology Center, 1310 Beulah Road, Pittsburgh, PA 15235

A. Burger, I. Clarkson, J. Schulteiss, P. Walstrom

Northrup Grumman Corporation, S. Oyster Bay Road, Bethpage, NY 11714

D. Hartman, G. Naumovich

Everson Electric Company, 2000 City Line Road, Bethlehem, PA 18017

\begin{abstract}
The TPX magnet preliminary design effort is summarized. Key results and accomplishments during preliminary design and supporting $\mathrm{R} \& \mathrm{D}$ are discussed, including conductor development, quench detection, TF and PF magnet design, conductor bending and forming, reaction heat treating, helium stubs, and winding pack insulation.

\section{INTRODUCTION}

The Tokamak Physics Experiment (TPX) is an advanced tokamak design with superconducting toroidal-field (TF) and poloidal-field (PF) magnets. From July 1994 through September 1995, the TPX magnet systems progressed from a national-laboratory-based conceptual design [1] to an industry-based preliminary design (Fig. 1). In addition, the team performed $R \& D$ to reduce uncertainties in performance and manufacturing. This paper summarizes the progress in
\end{abstract}

This work was performed under the auspices of the U.S. Department of Energy by Lawrence Livermore National Laboratory under contract number W-7405-Eng-48. the past 14 months, with emphasis on the R\&D efforts that will find more general applicability.

An integrated team of industries and laboratories worked together to develop the preliminary design. PPPL carried overall responsibility for the entire TPX project, and LLNL was responsible for overall leadership of the TPX magnet effort. A team from Babcock and Wilcox (B\&W), supported by General Atomics (GA) performed the preliminary design of the TF system, as well as R\&D efforts in conductor bending and forming and reaction heat treatment. A second team from Westinghouse Electric (WEC), Everson Electric, and Northrup Grumman was responsible for the design of the PF system, as well as R\&D on coil insulation and helium stubs. References [2] and [3] are final reports on these efforts. $\mathrm{R} \& \mathrm{D}$, analysis, and design in the areas of conductor, conductor joints, quench detection, local instrumentation and control, and coil leads and busses were the responsibility of LLNL, MIT, and PPPL. 


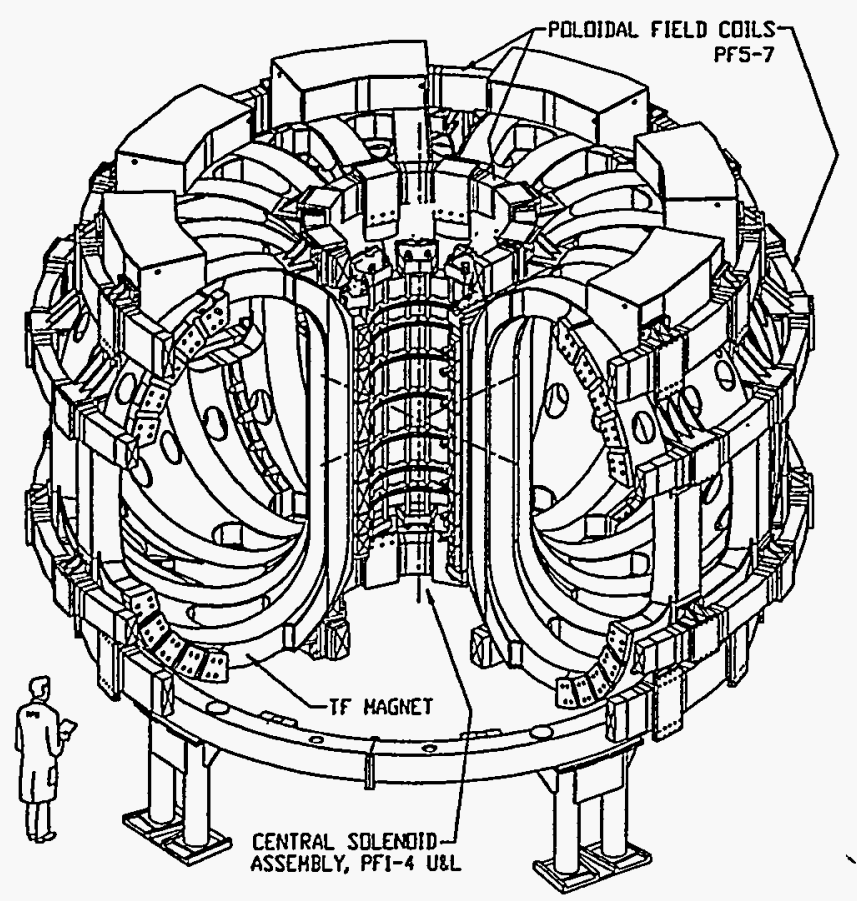

Fig. 1. TPX Magnet System

Both of the industrial teams also demonstrated their strong commitment to TPX and the U.S. fusion program by pursuing their own internally-supported $R \& D$ projects, which made important contributions to TPX. B\&W identified a new 3D insulation system to the project and performed initial development and testing of the 3D S2 glass materials that helped prove their viability for use in the winding pack insulation. WEC designed and constructed a full-diameter dummy CS coil, demonstrating all significant manufacturing process required for such coils.

During the course of the TPX magnet preliminary design and $\mathrm{R} \& \mathrm{D}$ effort, the key issues that drive the design of large, complex superconducting fusion magnet systems were identified and successfully resolved. A selection of these issues and their status are listed in Table 1.

\section{CONDUCTOR DESIGN AND DEVELOPMENT}

TPX magnets employ cable-in-conduit conductor (CICC), in one of three configurations, as shown in Table 2. The most critical R\&D issue associated with these conductor designs is the stability of the conductor under transient conditions: the "ramp-rate limitation" observed in other experiments. The TPX project addressed this issue by a series of subscale 27 strand subcable experiments, which were to be followed by a series of three full-scale, but short length, tests. To date, the 27-strand subcable tests showed excellent conductor performance in magnetic fields ramped at rates exceeding those in TPX $[4,5]$. This gives confidence that the conductor design will work as predicted, though this must be confirmed in full-scale tests. Preparation for full-scale conductor and joint tests is in progress, with the first full-scale 4-meter-long length of superconducting CICC completed. Two such samples were to be tested in the Pulsed Test Facility at MIT in 1996.
Table 1. List of Key Issues Addressed in Preliminary Design

\begin{tabular}{l} 
Component \\
\hline Conductor \\
Manufacture of strand to TPX \\
specifications \\
Cabling, including quench \\
sensors
\end{tabular}

Manufacture of conduit mat'1

Manufacture of long CICC

Ramp-rate performance limit

Full-scale demonstration

Winding packs

Straightening and bending conductor to form coil

Bending of leads

Tooling for coil winding

Uniform temp-time profiles in superconductor reaction

I908 conduit SAGBO control

Coil insulation mechanical strength

Coil insulation electrical performance

Coil insulation processes and tooling

Ground plane design and manufacture

Distortion during heattreatment

Helium stub design and process

successful tests and dummy coil demonstrated specified successful predictions and tests approaches spec'd, SAGBO not

observed in tests

Successful tests complete

Successful tests complete Specified

demonstrated

successful tests complete

Prototypes tested

Coil systems

Satisfy all operational requirements

Error fields and tolerances, alignment

Structure design and manufacturing

TF structure bolted joint design

Quench detection - signal:noise

Conductor joint design

Prototype test

Coil cases on PF coils

Complete

Complete

Complete

Complete

$\mathrm{V}$ sensor and FO sensor demonstrated

Prototype design

complete

future

Complete

Overall system design

Superconducting magnet design criteria

Operational flexibility space

Failure modes, effects, and criticality analysis

Quantitative reliability calc's

Detailed manufacturing plans

Self-consistent cost estimates

Leads and busses design
Complete

Complete

Complete

future

Complete

Complete

Complete 
Table 2. TPX Conductor Characteristics

\begin{tabular}{|l|c|c|c|}
\hline \multicolumn{1}{|c|}{ Conductor Type } & A & B & C \\
\hline \hline Use & TF & $\begin{array}{c}\text { Central } \\
\text { solenoid } \\
\text { and PF5 }\end{array}$ & PF 6 \& 7 \\
\hline Superconductor & Nb3-Sn & Nb3-Sn & NbTi \\
\hline Strand Cu:non-Cu & $2.5: 1$ & $3.5: 1$ & $2.5: 1$ \\
\hline Strand diameter (mm) & 0.78 & 0.78 & 0.78 \\
\hline Total strands & 486 & 360 & 360 \\
\hline No. of pure Cu strands & 0 & 120 & 120 \\
\hline $\begin{array}{l}\text { No. of superconductor } \\
\text { strands }\end{array}$ & 486 & 240 & 240 \\
\hline $\begin{array}{l}\text { Conduit material } \\
\text { Oo u ter }\end{array}$ & $\begin{array}{c}\text { Incoloy } \\
908\end{array}$ & $\begin{array}{c}\text { Incoloy } \\
908\end{array}$ & $316 \mathrm{LN}$ \\
\hline $\begin{array}{l}\text { Con d u it } \\
\text { dimensions (mm) }\end{array}$ & $22.30 \times$ & $22.30 \times$ \\
\hline Max current (kA) & 33.5 & 22.30 & 22.30 \\
\hline $\begin{array}{l}\text { Peak field at conductor } \\
\text { (I) }\end{array}$ & 8.5 & 5.3 & 14 \\
\hline $\begin{array}{l}\text { Total superconductor } \\
\text { mass (tonnes) }\end{array}$ & 40 & 5.6 & 9.9 \\
\hline Length per coil (km) & 1.1 & $0.3-0.6$ & $4.4-5.5$ \\
\hline
\end{tabular}

We also performed a series of tasks to develop the necessary capabilities for producing conductor [4]. Several strand vendors demonstrated their ability to meet TPX specifications, and preparations were made to begin procuring production prototype quantities. In the laboratory, we were able to meet critical tolerances in the production of conduit, and we successfully demonstrated the cabling of quench sensors within the cable. An industrial effort is in progress which will soon yield long lengths (several hundreds of meters) of fullscale dummy CICC. Together, these efforts give us confidence in the conductor design and the ability to manufacture it in industry.

\section{QUENCH DETECTION R\&D}

The TPX magnet system faces a severe challenge in reliably detecting magnet normal zones in the presence of voltages induced by plasma initiation, control, disruption, etc. An important goal of the past year was to develop and demonstrate reliable quench sensors with high signal-to-noise ratio, for TPX use. The system proposed for TPX $[6,7]$ includes a set of voltage sensors which are located within the superconducting cable, and hence cancel most inductive signals. Several experiments were performed which demonstrated adequate noise cancellation. A second sensor strategy, fiber optic (FO) thermometry, will be used in addition to the cowound voltage sensors. This approach is insensitive to electrical and magnetic noise, but is very sensitive to the temperature changes typical in normal-zone evolution. This has been demonstrated in small-scale experiments to give extremely clean quench signals. Several optical fibers will be enclosed in a stainless steel capillary tube in the center of the superconducting cable. Liquid helium flowmeters are one of the very few options for a repairable quench sensor. Recent thermal-hydraulic analysis has shown that the helium flow resulting from some quenches is so large that most flowmeters have insufficient dynamic range. No available flowmeter has yet been identified for this application, but work is in progress on several concepts.

\section{TOROMAL-FIELD MAGNET DESIGN}

The TF system consists of 16 identical coils, each with 84 turns of Type A CICC in a $7 \times 12$ array. The coils are enclosed and supported by a $316 \mathrm{LN}$ stainless-steel structure, which consists of coil cases integrated with intercoil structures. The system is constructed in 8 octants (Fig. 2), connected with precision bolted joints on both faces, insulated to limit eddy currents, to complete the 16-coil system [2].

One of the important challenges addressed during preliminary design of the TF system was to meet the TPX requirements for allowed magnetic field errors, which were stated in terms of toroidal (n) and poloidal (m) harmonic components of the normal field on a mathematically-defined "D-shaped" plasma surface [8]. Requirements were initially stated for the $(m, n)=(2,1)$ mode, as this relates to locked-mode plasma stability; further requirements were stated for other modes. To address these requirements, a systematic study was made of the effect of all six possible TF coil misalignments, three translational errors and three rotational errors, generating the harmonic coefficients associated with unit errors in each of these six basic degrees of freedom. This study revealed that the $(1,1)$ component was a more significant design driver for the TF system, and that the primary requirement for minimizing the $(1,1)$ error component from the TF system is to minimize radial coil misalignments. Having calculated the field errors associated with basic misalignments of individual coils, further studies were then conducted using a Monte Carlo approach to investigate the net errors which could be expected from the entire 16 coil system for specified tolerances. A later study then addressed the range of tolerances which must be achieved in order to meet the stated field error requirements. This last study indicated that radial displacements and rotation of TF coils about their vertical axis must be very carefully controlled, while tolerances for other misalignments could be relaxed. $[2,8]$.

The need to control coil radial misalignments and rotations was strongly reflected in the design of the structure. The preliminary design and manufacturing plan includes procedures which locate the winding pack precisely within the coil case and structure, and measure its position accurately with respect to accessible external fiducials. Precise alignment of the inner leg of the TF structure is also essential to ensure proper wedging. For these reasons, the preliminary design also includes a final machining step for each octant, as well as a bolted octant-to-octant joint on the outside of the structure, which incorporates insulated spacers that can be machined easily, if required, to precisely set the proper coil/structure alignment and preload at assembly.

Significant effort was directed at developing manufacturing plans, processes, and tooling, that addressed the unique needs of I-908 sheathed, $\mathrm{Nb} 3 \mathrm{Sn}$ superconducting conductor. We have chosen the wind, react, insulate approach for the TF coils. The coils will be not be wound, in the conventional sense, but rather they will be formed using a computer- 


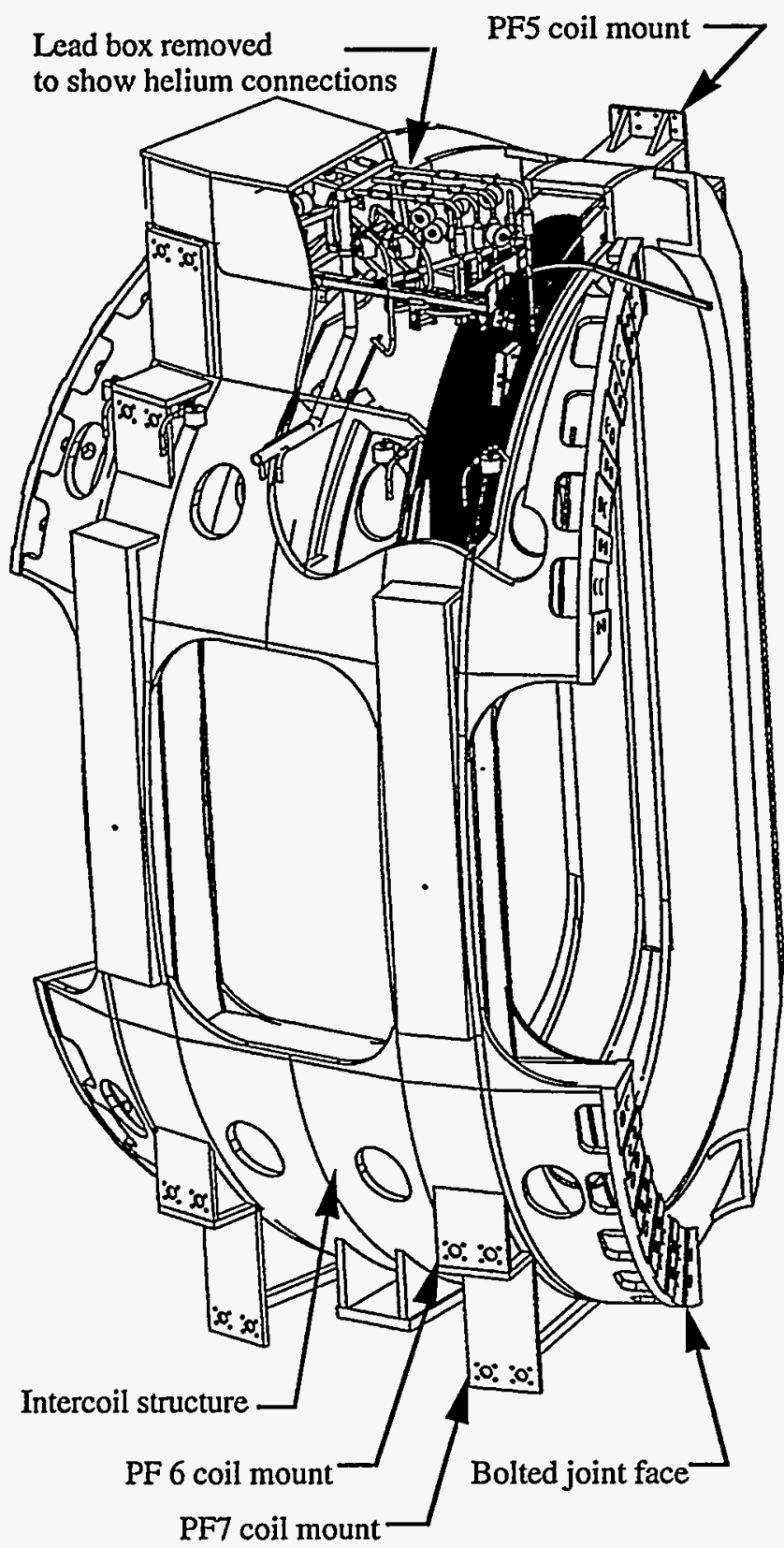

Fig. 2 - TF Octant, with lead box area sectioned

controlled roll bender with feedback instrumentation. CICC will be received on a spool, and the winding tooling will despool, clean, straighten, and then properly bend it continuously, while casting it into a stacking fixture of the proper shape. Development work has shown that careful control of the turn length is most crucial in obtaining a finished coil with regular turn-to-turn spacing, so measurement of the conductor length and marking of turns is an important feature of the tooling. Following winding of a coil, it is placed in a vacuum furnace, where the Nb3Sn superconductor is formed during an appropriate heat treatment cycle. This heat treat is carried out with strict control of the oxygen and water content both within the vacuum furnace (external to the CICC) and within the cable space inside the conduit, to avoid any possibility of cracking of the conduit from Stress-Assisted Grain-Boundary Oxidation (SÄGBO). Following reaction heat-treatment, each coil is placed in tooling which carefully separates the conductor turn-by-turn, and wraps on the kapton and S-glass insulation, and restacks it into a mold for vacuum-pressure impregnation (VPI). For the TF, VPI is performed in two stages: first to impregnate the windings and interturn insulation, and then, in a separate stage, to impregnate the ground-wrap insulation and the conductive ground plane, required for elimination of exposed voltages, electrostatic charge dissipation, for ground-fault detection. Finally, the monolithic winding pack is carefully aligned within the coil case, partially potted to hold it in position while the case is closed, and then potted into place. Final machining of the octant-to-octant bolting faces is performed as required to ensure proper fit-up at installation.

\section{POLOIDAL-FIELD MAGNET DESIGN}

The poloidal-field magnet system, Fig. 3, consists of seven pairs of superconducting coils, symmetric about the horizontal midplane of the tokamak. The first four pairs of coils, designated PF1 through PF4, upper and lower (U and L) are integrated by a single structure into a central solenoid (CS), which is supported by the TF structure at the center of the tokamak. All other ring-type coils are individually supported from mounts on the TF, with the last two pairs (PF6 and PF7, $\mathrm{U} / \mathrm{L}$ ) being mounted on the outboard legs of the TF structure $[9,3]$.

One of the principle challenges addressed during preliminary design of the PF system was the determination of all the electromagnetic forces on the $14 \mathrm{PF}$ coils. The combination of required operating modes, including single null, double null, disruptions, faults, high-current/low-current operation, and various operating points in li \& B space, resulted in thousands of load cases determining the forces on the coils. This was particularly important for the CS structure where forces tend to compress the structure, eject coils from the

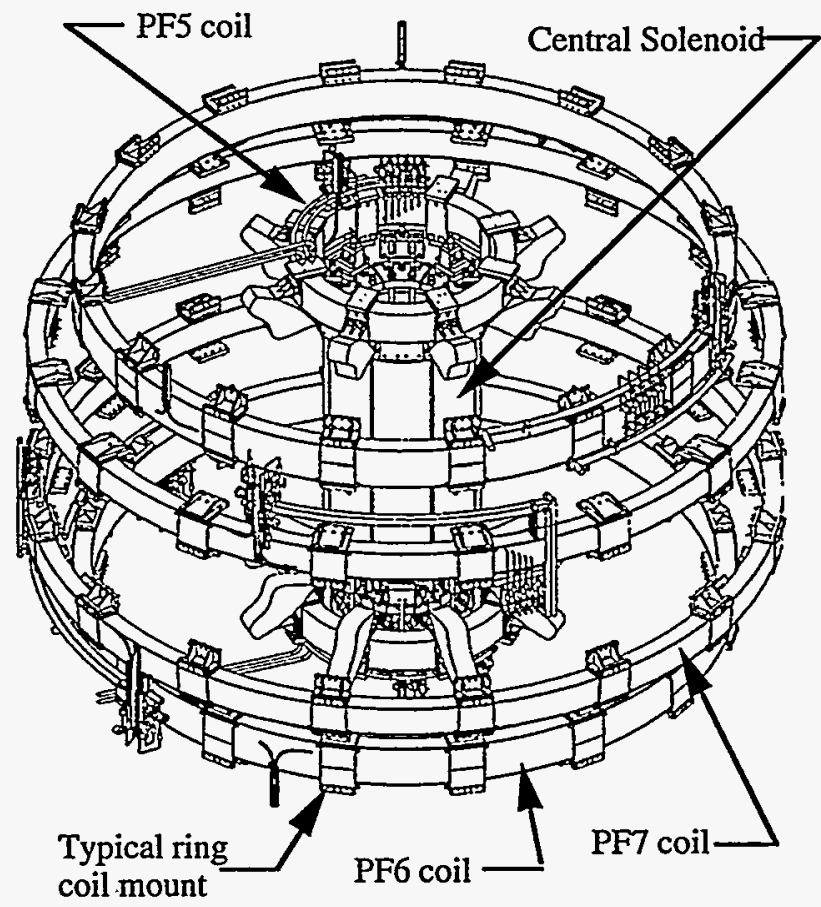

Fig. 3 - Poloidal-field coil System 
stack, or eject the entire stack from the bore of the TF. A systematic approach was used, in which all load cases were identified, non-limiting ones were eliminated, and the remaining subset was analyzed to determine the worse cases. These were used as the design points for the winding pack stresses, central solenoid preload, and supports.

The PF coils were all originally conceived with the individual windings vacuum impregnated together without structural coil cases. This was done to minimize eddy currents flowing in a case structure due to the large $\mathrm{dI} / \mathrm{dt}$ on initiation and plasma current ramping. However PF6 and 7 coils experience a large fringing magnetic field component from the outer leg of the TF coils, that results in a large bending moment. For this reason, cases were added for PF6 and 7; cases are segmented to reduce eddy current heating. The case is implemented using a novel design of bolting the cases around the wound coil and also using it as the VPI mold.

Another challenge was the incorporation of the cryogenic cooling lines, instrumentation, and current leads in the central solenoid structure. The 8 coils in the central solenoid require 68 electrically isolated cooling lines, 68 flowmeters, 30 filters, and 16 electrical leads. All equipment is installed inside the bore of the solenoid because of the small space between the TF and PF magnets. The overall height of the structure is also minimized so that the solenoid can be removed from the tokamak without any disassembly of the tokamak structure. All these restrictions result in a very compact arrangement of components that must be individually electrically isolated because of the potential for low voltage Paschen breakdown (160V) in a helium environment.

In order to allow for thermal contraction mismatches between the TF system and the CS and PF ring coils, the interfaces between the two magnet systems are made with radially compliant, toroidally stiff members. The central solenoid is hung from the TF with a set of radial flexures and the ring coils are connected with guided sliding joints to maintain the centering of the coils.

A similar approach is taken for the winding, heat treatment (except for PF6 and 7, which use NbTi), insulation, and vacuum impregnation as was used for the TF coils. The PF coils 1 through 5 are all wound in continuous spirals, while PF 6 and 7 are wound with constant radius turns and turn-toturn transitions. Proper positioning of the pancake-to-pancake joggles minimizes systematic field errors. VPI of each of the PF coils and conductive ground plane is performed in a single operation, unlike the TF coils. The impregnated individual coils of the CS are then magnetically aligned and assembled into the CS structure with the proper preload. One of the manufacturing challenges will be in maintaining adequate support for the brittle $\mathrm{Nb} 3 \mathrm{Sn}$ coil leads, some of which are up to 3.9 meters long.

\section{CONDUCTOR BENDING AND FORMING R\&D}

To support the preliminary design effort, and particularly the design of the long-lead tooling for producing the coil, we performed a program to develop data on the bending and forming characteristics of the CICC for all the TPX coils [2].
Short lengths of various types of conductors were bent in a small hydraulic fixture, to explore how small-radius bends could be made in the area of coil leads. The fixture was essentially a three-point bender, with a middle male die of various radii. The smallest die used (six-inch radius) occasionally caused buckling of the conductor, especially when using empty conduit (with no cable inside). For 7.5 inch and larger dies, correlations of springback versus bend angle were developed for all available CICC materials; these correlations showed good consistency within given material types, but variations between different material groups.

Longer lengths of dummy CICC were also formed in a continuous roll-bender to explore the potential problems in forming the coil windings. Although these trials showed consistency in bending performance among groups of similar materials with similar history, significant variations occurred between groups that experienced different processing histories. For example, single samples of CICC were repeatedly passed through the roll bender, with fixed roll setting, and then straightened. As the conductor received cold work in this manner, the resulting bend radius increased significantly. It was also found that hardness variations along the length of the conductor resulted in significant local changes in the bend radius.

This work revealed two important lessons. First, it will be vital to maintain careful control of the conductor processing history, to ensure uniformity of material properties, particularly hardness, along the length of each piece; we also must plan to provide conductor with sufficient length that some may be used for bending characterization prior to winding. Second, it was noted that even if the conductor bend radius is slightly incorrect, it can be corrected as the winding is clamped into place, provided that the bends were made in the correct location, i.e., that the points of tangency are correctly placed. This lesson has been incorporated in the tooling designs for both TF and PF coil forming.

\section{SUPERCONDUCTOR REACTION HEAT-TREAT R\&D}

The process of reaction heat-treating TPX Nb3Sn coils requires simultaneous careful control of the temperature uniformity throughout the winding pack and the heat-treat atmosphere, which is difficult for large windings. We developed a thermal model, and refined it based on experimental results, to accurately predict temperature profiles within the winding pack during heat treatment [2]. In order to provide space in the winding pack for introduction of insulation after reaction, spacers are inserted between conductors during winding. Analysis and testing showed that use of copper spacers can reduce temperature variations within the winding pack relative to steel or I-908 spacers. Measured temperature profiles within a short-length full-scale winding pack mockup appeared to be reasonable, but testing to determine the effect of variations on actual $\mathrm{Nb} 3 \mathrm{Sn}$ superconductor have not been conducted due to limited material availability. We also found that spacers made of I$908,316 \mathrm{LN}$, or copper all bonded to the outside of the conduit during reaction, to some degree. A spray-on coating of boronnitride was found to eliminate this problem. 


\section{HELIUM STUB DEVELOPMENT}

TPX magnets use single continuous lengths of CICC for each coil, to the maximum extent possible, to reduce the number of joints between CICC's. Thermal-hydraulic analysis shows, however, that liquid-helium cooling is required more often than once per coil, so it was necessary to develop an effective means of introducing a hydraulic connection, or helium stub, into a continuous CICC. The challenges are to produce a hole in the CICC, and then attach a tube without causing local mechanical or thermal damage to the superconducting cable. This is especially an issue for the PF6 and 7 conductor, which is $\mathrm{NbTi}$, and subject to thermal damage during stub welding. An acceptable process was developed in which the hole is made with a roto-bore, and a short tube is welded on the conduit using intermittent TIG welding and local heat sinks. The conduit weld can be inspected prior to welding of a longer tube onto the short tube. Tests using a real NbTi cable showed some degradation in critical current for several of the closest strands. Though this is not felt to be a significant problem, since there are so many strands that were undamaged, further testing is warranted [3].

\section{WINDING PACK INSULATION R\&D}

Development of the winding-pack insulation system for TPX coils was a significant effort in the past year $[3,10]$. The $R \& D$ effort was originally directed toward confirming the ability to vacuum-pressure impregnate (VPI) large cross-section winding packs, as used for TPX. However, after the conceptual design effort, detailed stress analysis of the winding-pack design revealed that high stresses were being generated within the glass-and-epoxy insulation. These stresses were predicted to be high enough to cause extensive cracking of the insulation, with the resulting possibility of electrical failure. Significant analytical and experimental effort was applied to understand the causes of this stress, and develop a design to mitigate the effects. Primary causes were eventually traced to anisotropic thermal-contraction for typical fiber-reinforced insulations, mismatch of coefficient of thermal expansion between insulation and conductor materials, and moments resulting from winding-pack stresses being transmitted through rectangular conductors with rounded corners. Several approaches were identified to reduce the problem and mitigate the effects. The resulting insulation system uses: kapton film wrapped (unbonded) directly on the conductor to provide robust electrical insulation even if cracking of the bulk insulation occurs; a "slip plane" between the conductor and the kapton to minimize the stress state within the fiberglass insulation; and "three-dimensional" fiberglass materials to reduce anisotropy and the resulting propensity for cracking. Several large-scale tests were conducted in which insulated $5 \times 5$ conductor arrays were thermally cycled, mechanically cycled while cold, and electrically cycled. All of these tests showed acceptable electrical and mechanical performance for multiple lifetimes at elevated voltage, despite many small internal cracks in the areas between conductors. Based on this effort, we have redefined the design acceptance criteria for composite cryogenic coil insulation. Though we feel we have overcome this problem sufficiently for preliminary design, further testing and optimization would be appropriate in the future.

\section{CLOSING REMARKS}

With the unexpected cancellation of TPX, it is worth emphasizing the vital building blocks this engineering team of US industrial and national laboratory participants laid on their journey toward the affordable tokamak. After four years and a \$70M US government and industry investment in TPX, this team appears to have mastered the key scientific, engineering and manufacturing challenges that have prevented the deployment of a fully superconducting tokamak magnet system. For only a fraction of the cost of other alternatives, the TPX team was poised to deliver the promise of the next generation advanced tokamak in a scant 7 years, precisely in time to stimulate the US scientific quest for affordable fusion power. But it is not to be. Poised like Moses on Mt. Nebo overlooking the Jordan River, TPX team members see the promise; but, like Moses, are unable to cross into the Promised Land. It remains for the international community to walk forward.

\section{ACKNOWLEDGMENT}

We acknowledge the countless hours of hard work by all the members of the TPX magnet team, and especially the dedication demonstrated by both the corporations and the individuals of the teams from $B \& W / G A$ and WEC/EE/NG.

\section{REFERENCES}

[1] R. Bulmer, et. al., "TPX magnet system status," Fusion Technology 1994, pp. 933-936.

[2] L. R. Pedrotti, tech contact, "Tokamak Physics Experiment (TPX) Toroidal Field Magnet Final Report," (final report authored by the team from Babcock and Wilcox Company under contract with LLNL), Lawrence Livermore National Laboratory document UCRL-CR-121738, September 22, 1995.

[3] M. Jackson, tech contact, "Tokamak Physics Experiment (TPX) Poloidal Field Magnet Final Report," (final report authored by the team from Westinghouse Electric Corporation, Everson Electric Company, and Northrup Grumman Corporation under contract with LLNL), Lawrence Livermore National Laboratory document UCRL-CR-121739, September 22, 1995.

[4] J.P. Zbasnik, N.N. Martovetsky, S.M. Hibbs, J.H. Schultz, R.D. Pillsbury, $\mathrm{Jr}$, and J.C. Citrolo, "TPX superconducting cable-in-conduit 1995 design and development progress," 16th IEE/NPSS Symposium on Fusion Engineering, Sept. 30 - Oct. 5,1995 , in press.

[5] S. Jeong, et. al., , "Ramp rate limitation experiments and analysis in support of the TPX magnets" 16th IEE/NPSS Symposium on Fusion Engineering, Sept. 30, 1995, in press.

[6] M.R. Chaplin, ett. al., "Local I\&C for the TPX TF and PF magnets" 16th IEE/NPSS Symposium on Fusion Engineering, Sept. 30, 1995, in press.

[7] M.R. Chaplin, N.N. Martovetsky, J.P. Zbasnik, J.H. Schultz, S. Pourrahimi, S.P. Smith, P. Wang, "Co-wound voltage sensor R\&D for TPX magnets," 16th IEE/NPSS Symposium on Fusion Engineering, Sept. 30,1995 , in press.

[8] J.A. Leuer and J.L. Luxon, "Impact of PF and TF coil misalignment on $m=2, n=1$ plasma error fields in TPX," 16 th IEENPSS Symposium on Fusion Engineering, Sept. 30 - Oct. 5, 1995, in press.

[9] H. Calvin, et. al., "Preliminary design overview of the superconducting TPX poloidal field magnet system" 16th IEENPSS Symposium on Fusion Engineering, Sept. 30 - Oct. 5, 1995, in press.

[10] P. Sanger, et. al., "Insulation system development activities by the Westinghouse TPX team for the TPX magnet system" 16th IEE/NPSS Symposium on Fusion Engineering. Sept. 30 - Oct. 5, 1995, in press. 